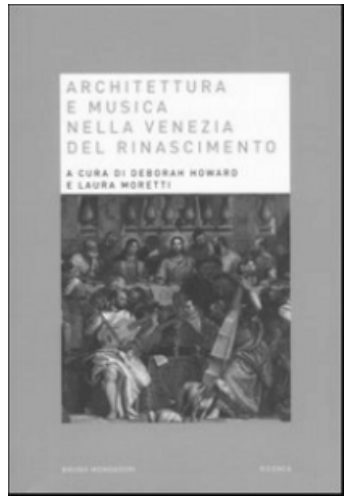

Keywords: Renaissance

Book Review

Deborah Howard and Laura Moretti (eds.)

\title{
Architettura e Musica nella Venezia del Rinascimento
}

Milan: Mondadori, 2006.

Reviewed by Sylvie Duvernoy

Via Benozzo Gozzoli, 26

50124 Florence ITALY

sduvernoy@kimwilliamsbooks.com

architecture, acoustics, Palladio

This publication is the proceedings of an international conference which was held on the Isola San Giorgio in Venice on 8-9 September 2005, organized by both the Fondazione Scuola di San Giorgio and the University of Cambridge, where the two editors of the volume, Professor Deborah Howard and Architect Laura Moretti, teach and work.

As professor Howard explains in her introduction to the proceedings:

The book represents the first stage in an international, interdisciplinary research project based at the Centre for Acoustic and Musical Research in the Renaissance Architecture (CAMERA) in the Department of History of art, University of Cambridge and funded by the Art and Humanities Research Council of the UK [p. 8-9].

The papers of the book are written either in English or in Italian but all the abstracts are in both languages: the book is therefore accessible to a vast international readership.

During the conference on the Isola San Giorgio, the question of the direct relationship between architecture and music in the Renaissance was approached mainly from the standpoint of acoustics, and the architectural spaces that were studied were the churches and chapels of Venice of the sixteenth century. The field of inquiry presented in the proceedings is therefore narrower than what the general title of the book, Architettura e Musica nella Venezia del Rinascimento, might suggest at first sight, but it is indeed interesting and discussed in depth. Churches are multifunctional buildings which have to satisfy several requirements that may be related either to liturgy (mass and sermons) or to festivities (music and choir singing). In addition they are composed of various interior spaces and volumes that interact with one another through openings and wide passages that alter the intrinsic acoustics qualities of each space. The research presented here focuses on the interaction between three contemporary aspects of sixteenth-century Venetian culture: the scientific knowledge of acoustics, church architecture and the musical innovation of choral polyphony.

Although the scholars attending conferences on specific topics are usually already experts in the field that is going to be discussed, two of the first papers of the book are short lessons for neophytes on the bases of acoustics and architectural form, and especially on the

Nexus Network Journal 10 (2008) 379-380 NEXUS NETWORK JOURNAL - VOL. 10, NO. 2, 2008379 
state of knowledge of architectural acoustics in the late Renaissance. Those papers are fundamental for the comprehension of the further researches, since they seem to present the common criteria for evaluating the architectural spaces under investigation, and they indeed provide the non-specialist but interested reader with the necessary basic notions, without which their colleagues' efforts would be less accessible. Unfortunately there is no similar introduction outlining elementary information about the musical evolution of the sixteenth century and the elaborate form of choral polyphony introduced in Venice at the instigation of the doge Andrea Gritti, for which every church and chapel had to adapt its interior design, permanently or occasionally.

The architectural spaces that are studied are both ancient churches and newly built monuments. In fact,

while a number of the city's roughly 150 churches where indeed constructed in the sixteenth century, almost all the buildings dated back to earlier periods and had "survived" into the sixteenth century with or without modifications. Sixteenth-century polyphony was performed in all those churches, regularly or intermittently [D. Bryant, E. Quaranta, F. Trentini, p. 261].

The two main monuments with which scholars deal in their process of research are the two major examples of the two categories: the cathedral of San Marco and the church of San Giorgio Maggiore. The first one illustrates evolution and adaptation, as it is a church whose form evolved through time and whose transformations went on during the Cinquecento when polyphonic choral music first developed. The second one is the example of modernity, since it was built in the sixteenth century by Palladio in the very days of musical innovation.

The researches presented in this volume will surely offer interesting clues to scholars involved in the study of relationships between mathematics and music, which is a recurrent topic of discussion in the pages of the Nexus Network Journal and at the biennial Nexus conferences. And although the field of research presented in this book is very narrow and specific, it considerably enlarges the discussion about architecture and music, which is too often restricted to the question of harmonic proportions inherited from Antiquity and their numerical applications in the geometric patterns of Renaissance architecture.

\section{About the reviewer}

Sylvie Duvernoy is the Book Review Editor for the Nexus Network Journal. 